\title{
FEVER IN HEART FAILURE
}

\section{RELATIONS BETWEEN THE TEMPERATURES OF THE INTERIOR AND THE SURFACE OF THE BODY}

\author{
By J. MURRAY STEELE \\ (From the Hospital of the Rockefeller Institute for Medical Research, \\ New York City)
}

(Received for publication July 2, 1934)

Fever has for a long time been observed to be a very frequent symptom during heart failure. Often the elevation of temperature is associated with infectious processes, often with non-infectious ones as, for example, infarction of various organs, cerebral hemorrhage or hyperthyroidism. Many times meticulous search fails, however, to bring to light any of these conditions. It has then been generally assumed that one of the more familiar processes is present but has escaped detection. In lungs already the seat of chronic passive congestion bronchopneumonia might easily remain undiscovered.

Fever during the course of heart failure has remained inexplicable so frequently that several observers have developed hypotheses to account for its occurrence. Cohn and Steele (1) reviewed these briefly and supported with clinical evidence the idea that heart failure itself may lead to the elevation of rectal temperature. The evidence consists in having related in point of time the appearance of the signs of heart failure with the appearance of fever when no recognized causes of fever are discoverable.

It is a venerable observation that people with "poor circulation" have cold hands and feet while the extremities of patients with infectious diseases possessing presumably normal circulations are hot. This important difference suggests the desirability of studying the relations between the temperature of the surface and that of the interior of the body. Changes in the conditions of the environment undoubtedly influence this relation and must therefore be kept under control or, in any event, carefully recorded. Calorimetry did not appear to be the best method to employ in this study since the problem concerns not a discrepancy between heat produced and heat lost but the mechanism by which thermal equilibrium is maintained or established within the body under conditions which differ from those encountered in normal individuals.

Knowledge of the variations in temperature of the surface in conse- 
quence of bodily activity and of changes in environment has been contributed by so many observers that a complete list of citations has not been attempted. Benedict perhaps has been responsible, more than any other individual, for arousing interest in the subject. Together with a number of collaborators he has shown that, although much more variable than internal temperature, the temperature of the surface is fairly constant and uniform when the environmental conditions are adjusted so as to meet the subject's requirements for personal comfort. He has found that the trunk varies usually between 33.5 and $36.5^{\circ} \mathrm{C}$. (2). The temperature of the extremities is not nearly so constant. When the environmental temperature is approximately $25^{\circ} \mathrm{C}$. it appears though that, in subjects at rest and comfortable, the surface of the extremities too, is fairly uniform. In 12 girls the surface temperatures ranged from $30.3^{\circ} \mathrm{C}$. to $35.2^{\circ} \mathrm{C}$. and in four women from $33.2^{\circ} \mathrm{C}$. to $35.5^{\circ} \mathrm{C}$. At rest the average temperature of the skin is about $34^{\circ} \mathrm{C}$. (3). With Parmenter he has shown that the surface temperature falls with fall in environmental temperature. This fact has been confirmed by many observers, notably by Talbot (4) who confirms also the fact that the immediate effect of exercise is to lower the surface temperature. Talbot makes clear that the temperature of the extremities varies to a greater extent with the temperature of the environment than does that of the trunk. He observed that the usual range of relative humidity has little if any effect. Foged (5) gives the range of temperatures of the abdominal skin as 33.6 to $36.9^{\circ} \mathrm{C}$. These figures agree fairly closely with those of Benedict and were obtained from records of more than 2700 observations in normal people. The feet he finds extremely variable. The minimum found in normal individuals was $22.7^{\circ} \mathrm{C}$., the maximum $34.3^{\circ} \mathrm{C}$. Foged emphasizes the important observation that symmetrically located points on the surface of the body are at the same temperature. Symmetrical points on the two sides of the body differ by $0.5^{\circ} \mathrm{C}$. or less in 75 per cent of his observations. The greatest difference noted is $1.2^{\circ} \mathrm{C}$. Ward (6) correlated sensations of comfort with surface temperature in the region of the carotid artery and on the forehead and her figures fall within the range found by Benedict.

A very interesting diurnal variation has been reported by Kirk (7). He noticed that in all except debilitated individuals the temperature of the feet rose each night just before the onset of sleep in a fashion quite similar to that noted by Ipsen (8) during the initial stages of anesthesia. The reaction to anesthesia has since been used extensively as a test for distinguishing local circulatory disorders due to structural arterial disease from those due to "spasm" of the vessels $(9,10)$. Gibbon and Landis (11) have more recently shown that simply by immersing one or more extremities in water at $45^{\circ} \mathrm{C}$., excellent dilation of the vessels in the extremities not so treated may be obtained. This was an extension of the method of Lewis and Pickering (12) of obtaining peripheral dilatation by heating 
the whole body. All of these reactions serve to emphasize the potential variability of the temperature of feet and hands.

From the foregoing paragraphs it appears that in spite of the accumulation of considerable data on factors which influence the temperature of the skin and the extent to which temperature may change under various circumstances, a clear conception is still lacking of the extent and form of the ordinary diurnal variation of many points on the skin of a normal individual at rest. In view of the variability of surface temperatures, knowledge of the form and extent of the usual daily variations is necessary for describing their unusual variations. The study of normal individuals as well as of cardiac patients at rest under a set of uniform environmental conditions and over periods of observation lasting at least twenty-four hours was, therefore, undertaken.

A description of the equipment and procedure used follows :

1. A room of approximately constant cooling power was employed in which the temperature was maintained between $20.5^{\circ}$ and $21.5^{\circ} \mathrm{C}$., the relative humidity between 40 and 50 per cent and the rate of movement of air between 2 and 3 meters per second. The sum of the effect of these three factors was measured at intervals by means of Hill's kata-thermometer. The resultant cooling power varied between 4.0 and 4.4 (dry) and between 15 and 16 (wet) millecalories per square centimeter per second.

2. Surface temperatures were measured by means of copper-constantan thermocouples. In a few of the earlier observations a single thermocouple was employed. Considerable disturbance of the individual under observation was entailed in measuring, by a single exploring thermal junction, many points scattered widely over the body. Before continuing the study, therefore, ten thermocouples were made and adjusted so that they could be held in place throughout the period of observation. The units were made as nearly similar as possible. Number 30 gauge wire was used for both copper and constantan elements. The constantan wire was carefully tested for its uniformity of composition by immersing the whole length, a foot at a time, in hot water while the ends were connected to a galvanometer. Each unit was adjusted to the same sensitivity by altering the length of the constantan element. The junctions to be kept at constant temperature were placed in a bath for the purpose described by Clark (13). Some difficulty was experienced in obtaining thermocouples with the same zero point. The differences were due partly to the type of temperature bath used and partly to the switches and circuit connections. Correction involved, however, only simple addition to or subtraction from the reading obtained of $0.1^{\circ}$ or, in one instance $0.2^{\circ} \mathrm{C}$. The copper poles of the thermoelectric units were connected by telephone cable (16 gauge copper wire) to a two-way ten-point rotary switch (Leeds and Northrup) by means of which any thermocouple could be quickly connected to the galvanometer. The switches, galvanometer, lamp and scale were located in an adjoining room. The galvanometer was a Type $R$, Leeds and Northrup moving coil suspension of $12 \mathrm{ohms}$ resistance with a balistic period of 7 seconds. A variable resistance was introduced in order that the sensitivity could be so adjusted that $1 \mathrm{~cm}$. deflection of the beam of light was equal to $1^{\circ} \mathrm{C}$. change in temperature. A change of $0.1^{\circ} \mathrm{C}$. was therefore easily read. 
The apparatus was calibrated in a well stirred water bath with a Bureau of Standards thermometer. Under these circumstances subsequent readings of the temperature of the water by means of the thermocouple did not differ from that read on the standard thermometer by more than $\pm 0.025^{\circ} \mathrm{C}$. The accuracy of thermocouples as applied to measurements of surface temperature will be considered later.

The procedure adopted for a period of study was as follows. The subject was placed in the room of constant cooling power, in bed, at 8 A.M., one to one and one-half hours before measurements were begun. The thermal junctions were made fast to the skin by adhesive tape at 10 points (Fig. 1). One

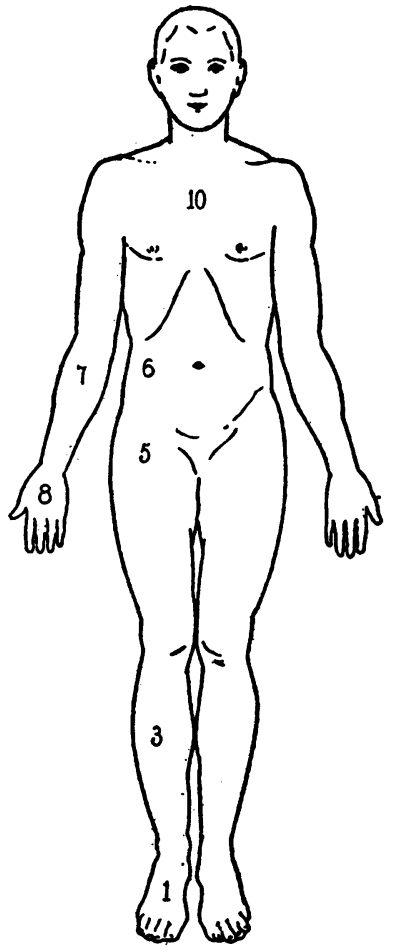

a

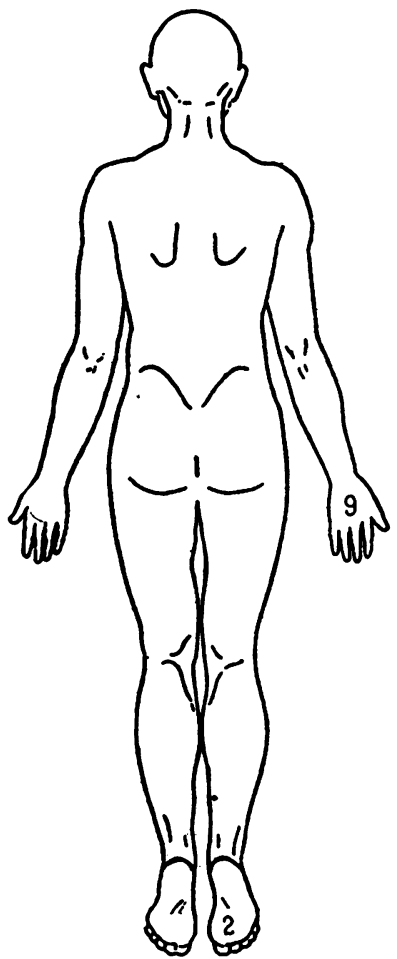

b*

Fig. 1. Outline Drawings Are Shown of the Anterior (a) and Posterior $(b)$ Surfaces of the Body to Show Position at Which ThermoCOUPLes Were Placed.

side only of the body was studied because of Foged's (5) observations on the similarity of temperature of the two sides. The patient enjoyed much greater freedom by use of this procedure. The temperature of the surface at points on the left side similarly placed to those on the right were taken, however, at the beginning of each experiment. Unusual differences between the two sides were not encountered. The thermal junctions were mounted on bits of cork measuring approximately $10 \times 5 \times 3$ millimeters which prevented the adhesive 
tape from touching the skin in the region immediately adjacent to the thermocouple. A thermal junction encased in a rubber catheter was inserted to a depth of 10 centimeters into the rectum; one enclosed in a cage with vents for circulation of air was laid at the foot of the bed beneath the covers.

Since the study was conducted on patients, some of whom were seriously ill, it was impossible to deprive them over a long period of time of clothing. Every effort was expended, however, to see that the coverings employed were similar. The usual cotton pajamas of the hospital were worn. The bed clothes were always identical and consisted in (1) a standard hospital sheet and (2) a bedspread between which (3) one of two medium-weight wool blankets, selected because of their similarity in weight and texture, was placed. The diet consisted of 1800 calories with relatively little protein. The temperature of food and fluid was not greater than body temperature nor less than room temperature. Baths were omitted. The hands and face were cleansed quickly with a cloth dampened with water at room temperature and quickly dried. This was always done immediately after the 8 A.M. and 5:30 P.M. records were obtained. Activity was limited to reading, but no effort was made to maintain any particular position. Change of position, unusual exposure of a part of the body, placing of the hands under the covers, eating, sleeping, waking and any unusual occurrences were recorded in the nurse's notes. Unless specifically mentioned drugs were not given immediately before or during the period of observation.

Readings of the temperatures at the thermal junctions were taken every halfhour, occasionally in cases of rapid change, every quarter of an hour. Readings of the wet and dry bulb thermometers were recorded every two hours. In addition a continuous record of room temperature was obtained by means of a Tycos recording thermometer. The rate of consumption of oxygen was measured by means of a Benedict-Roth apparatus before breakfast on the morning on which the test ended in order that the rate of heat production at the time of the test might be estimated.

The records of the individuals studied are summarized in Tables I and II.

\section{RESULTS}

Few facts of diurnal variation in biology are more frequently recorded or better known than the regular daily fluctuation of internal, usually rectal or oral, temperature in man. From the data which are the subject of the present report it is apparent that under constant environmental conditions the surface of the body too, is subject to a fairly regular diurnal variation in temperature but that it is more easily influenced by the conditions of the environment. When the subject is at rest in bed in a room with an environmental temperature of about $20.5^{\circ}$ to $21.5^{\circ} \mathrm{C}$. variations somewhat as follows take place. The temperature of the surface of the trunk changes least, that of the extremities most. The direction of change in temperature of the extremities is in general opposite to that of the rectum; ${ }^{1}$

1 The same results have been obtained by Heiser, F., and Cohen, L. H., who have published a composite curve of a number of individuals each of whom was studied over a long period of time. J. Industrial Hyg., 1933, 15, 243. Diurnal variations of skin temperature. 


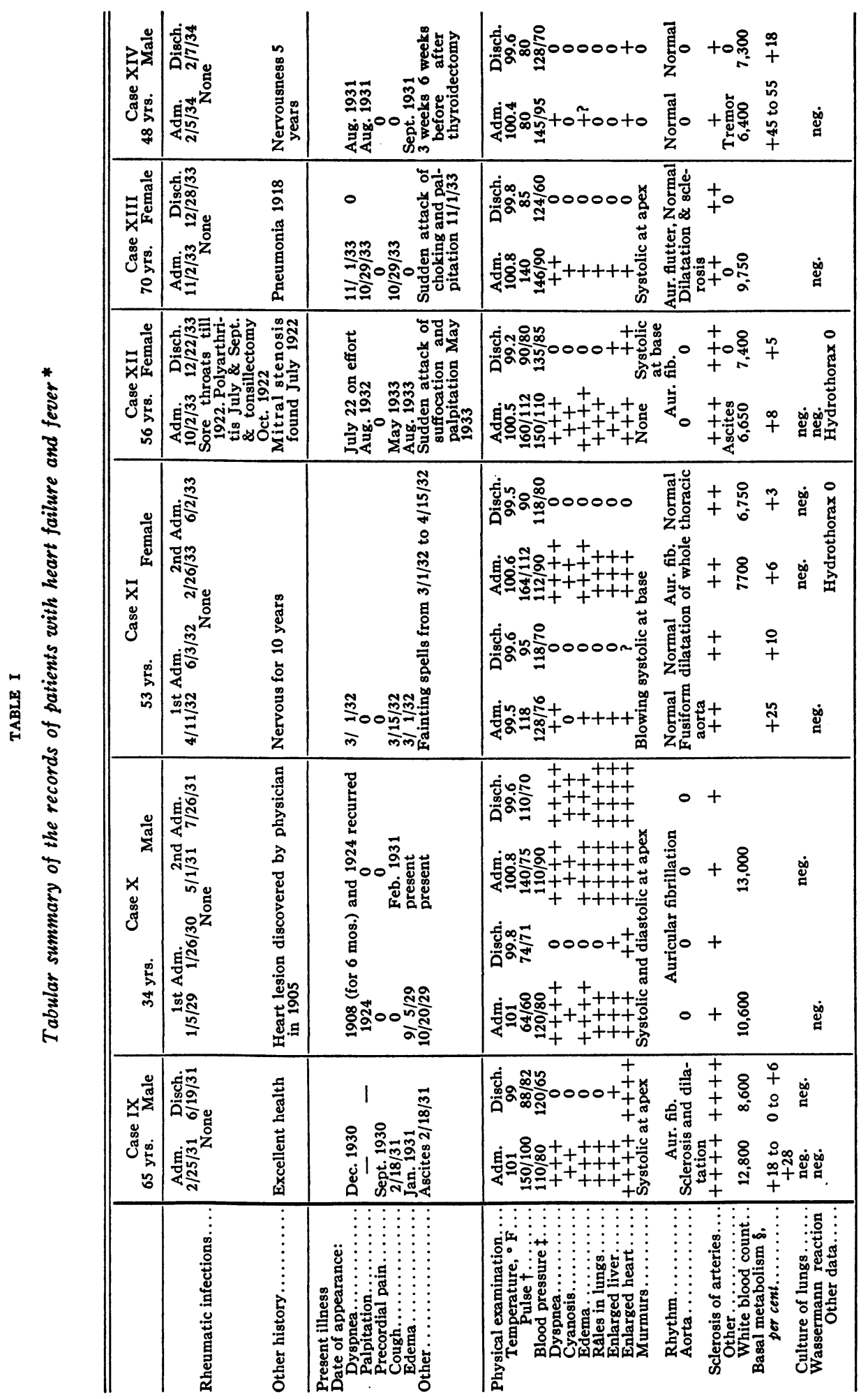




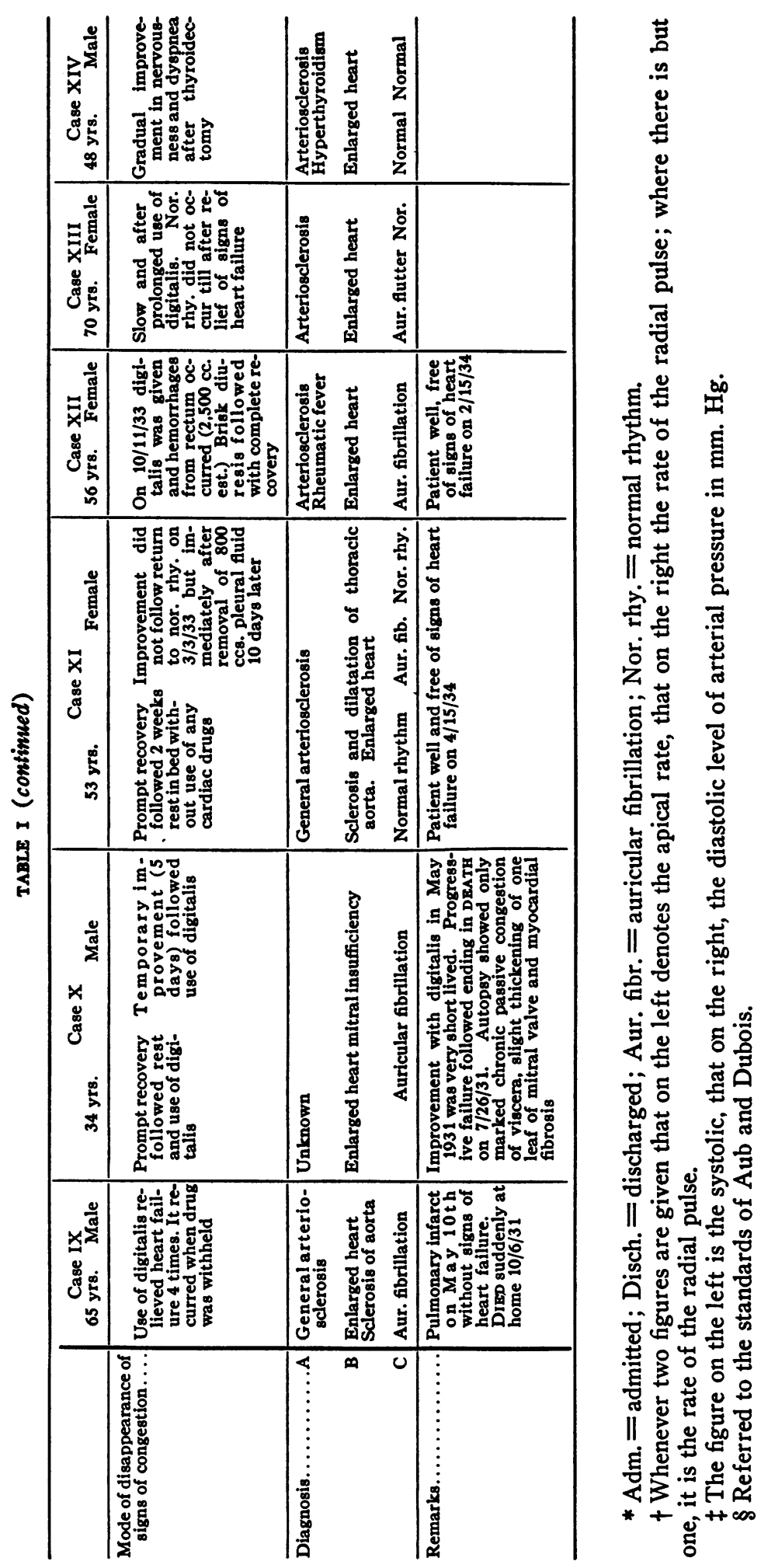


TABLE II

Data concerning individuals used for control

\begin{tabular}{|c|c|c|c|}
\hline $\begin{array}{c}\text { Case } \\
\text { number }\end{array}$ & Age & Sex & Condition at time of recording surface temperatures \\
\hline & years & & \\
\hline I & 33 & Male & Normal \\
\hline II & 52 & Male & Normal-convalescent neuritis of left musculo-spiral nerve \\
\hline III & 51 & Male & Normal-recovered lobar pneumonia \\
\hline IV & 35 & Female & Normal \\
\hline $\mathbf{V}$ & 37 & Female & $\begin{array}{l}\text { (a) Pulmonary abscess following secondary atypical pneu- } \\
\text { monia. Temperature } 101-103^{\circ} \mathrm{F} \text {. } \\
\text { (b) Normal-five months after subsidence of fever }\end{array}$ \\
\hline VI & 27 & Female & $\begin{array}{l}\text { Rheumatic endocarditis, aortic stenosis without signs of heart } \\
\text { failure }\end{array}$ \\
\hline & & & $\begin{array}{l}\text { (a) During attack of acute pharyngitis. Temperature } 100- \\
101^{\circ} \mathrm{F} \text {. } \\
\text { (b) One month after fever had ceased }\end{array}$ \\
\hline VII & 35 & $\mathrm{Ma}$ & Acute rheumatic polyarthritis. Temperature $100-101^{\circ} \mathrm{F}$. \\
\hline VIII & 34 & Female & $\begin{array}{l}\text { Subject of transient attacks of complete auriculo-ventricular } \\
\text { heart-block } \\
\text { (a) Complete heart-block } \\
\text { (b) Normal rhythm }\end{array}$ \\
\hline
\end{tabular}

as the rectal temperature rises during the early morning hours, that of the skin of the extremities falls and remains low or gradually increases during the day. At or just before the time when the rectal temperature begins to decline during the evening, the surface of the extremities rises and usually attains and holds its maximum while the rectal temperature is at its minimum (Figs. 2a (Case I) and $3 \mathrm{~b}($ Case V)). Even under the conditions which were imposed the extent of change of the extremities varied from person to person to a considerable degree (compare Figs. 2a and 3b). Examples of extreme exaggeration of diurnal variation have been observed to occur in a patient with heart block but without heart failure (Fig. 4, Case VIII) and in a patient with arterial hypertension.

In each individual the form of the changes in surface temperatures appears to be constant and to be reproduced with considerable regularity provided, of course, that the environmental conditions are similar. The rather unusual type of curve shown in Figure 4a (Case VIII) is reproduced almost exactly in Figure $4 \mathrm{~b}$ three months later. Whenever normal subjects were studied under the same conditions on more than one occasion the curves were quite similar. Opportunity to study one individual who had been a night-watchman for twenty-five years presented itself. There was no marked difference in the time of maximal and minimal temperatures of either surface or rectum. The form of the record obtained was similar to that obtained from individuals working during the day.

As the temperature of the environment rises above $20^{\circ} \mathrm{C}$. variation of the temperature of the extremities tends to become smaller until at about 


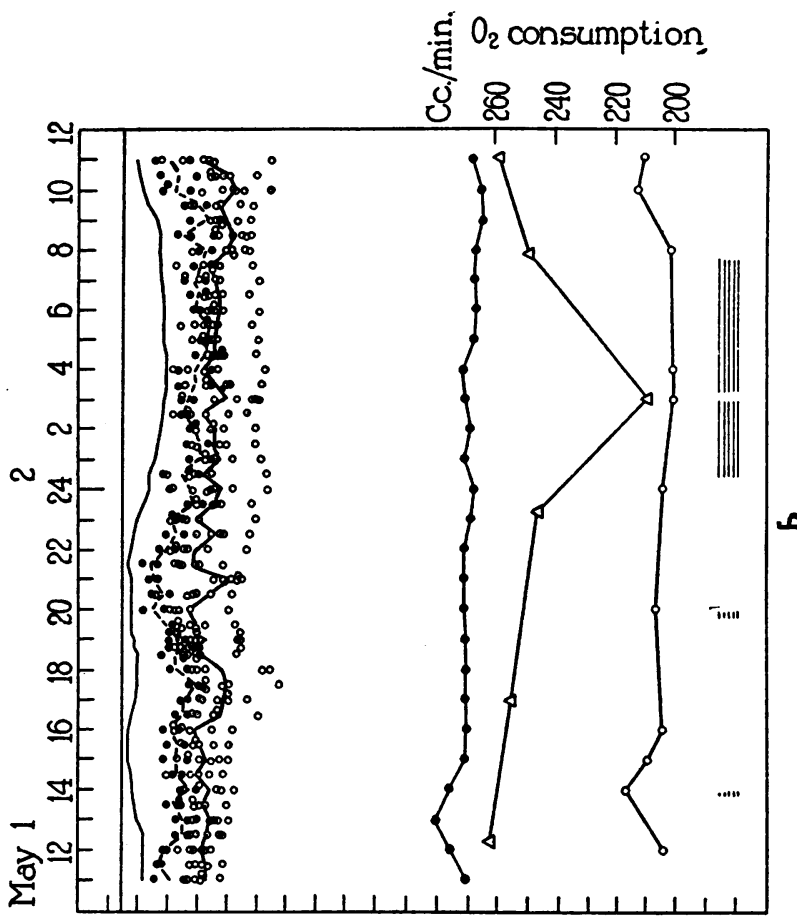

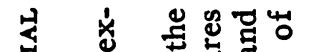

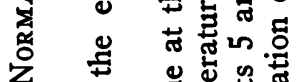
《岁㤩总营

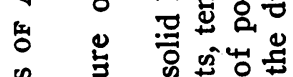

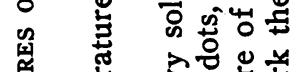

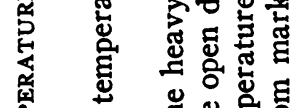

.

舁

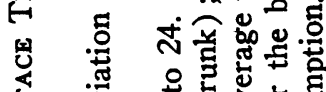

$\rightarrow$

焉 0 式空

थ $>\quad \varepsilon 0$

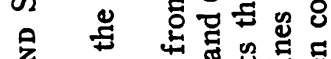

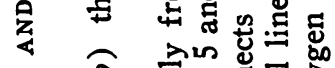

는

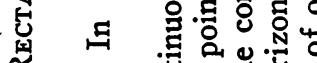

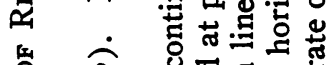

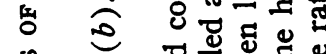

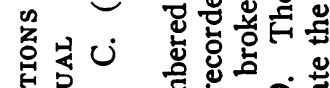

施 छ

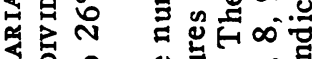

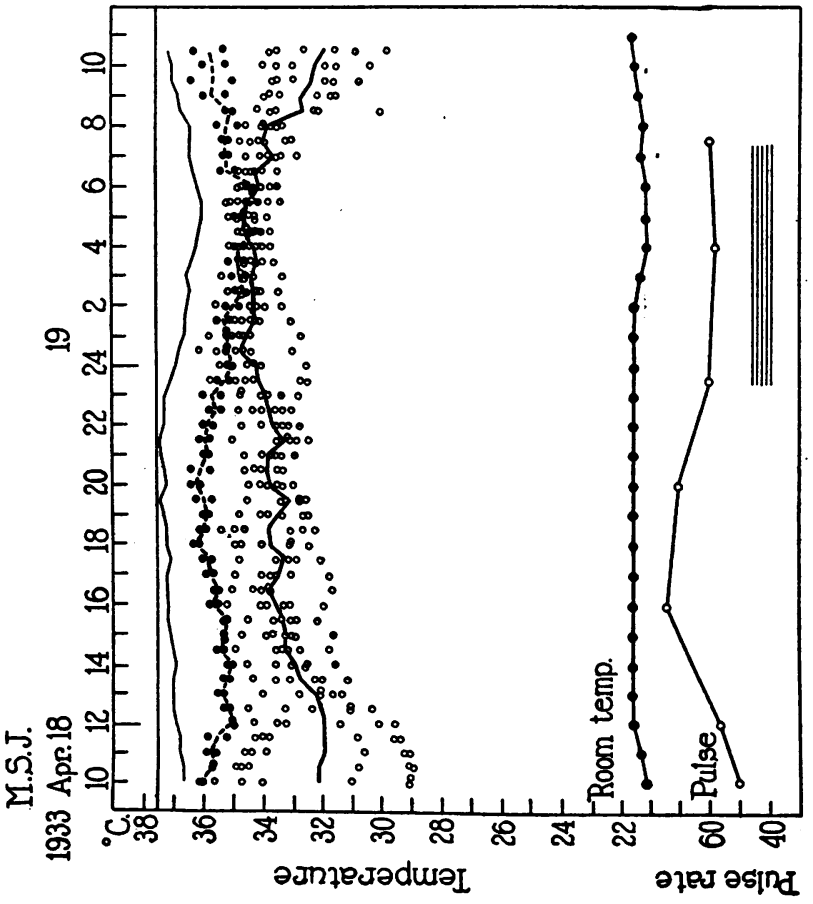

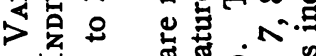

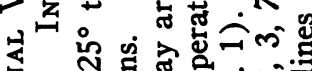

\% N.

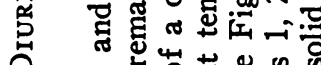

○ प

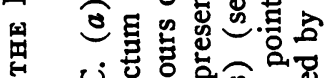

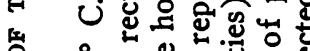

皮

z त

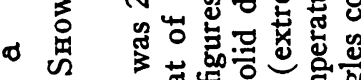

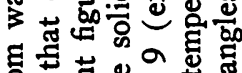

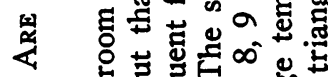

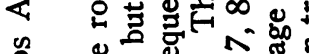

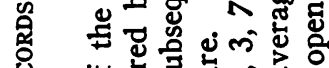

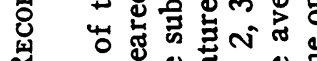

幽

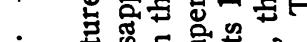

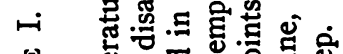

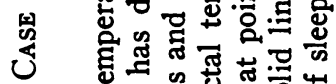

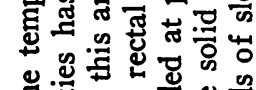

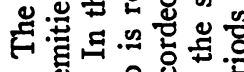

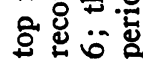




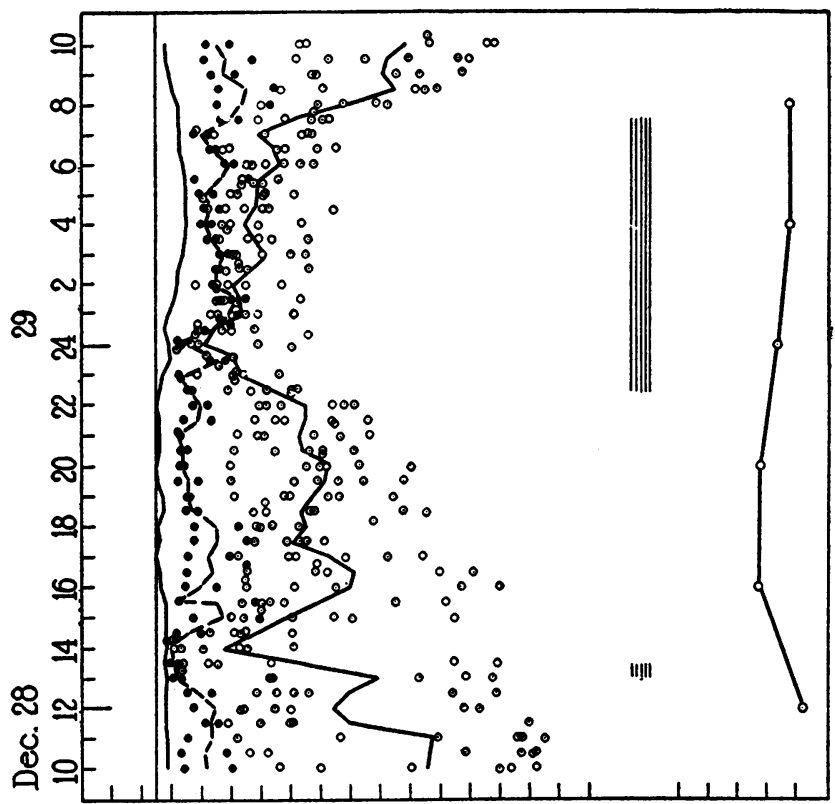

2

完 운현

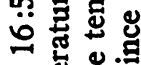

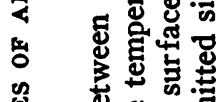

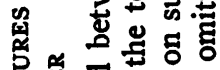

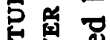

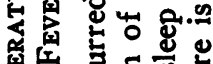
医 可的

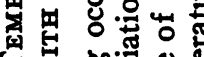

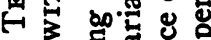

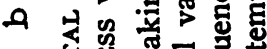

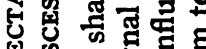

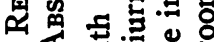
喓焉 द ह 당 ه : ชั 号范士 थम काष

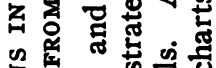

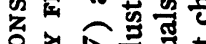

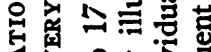

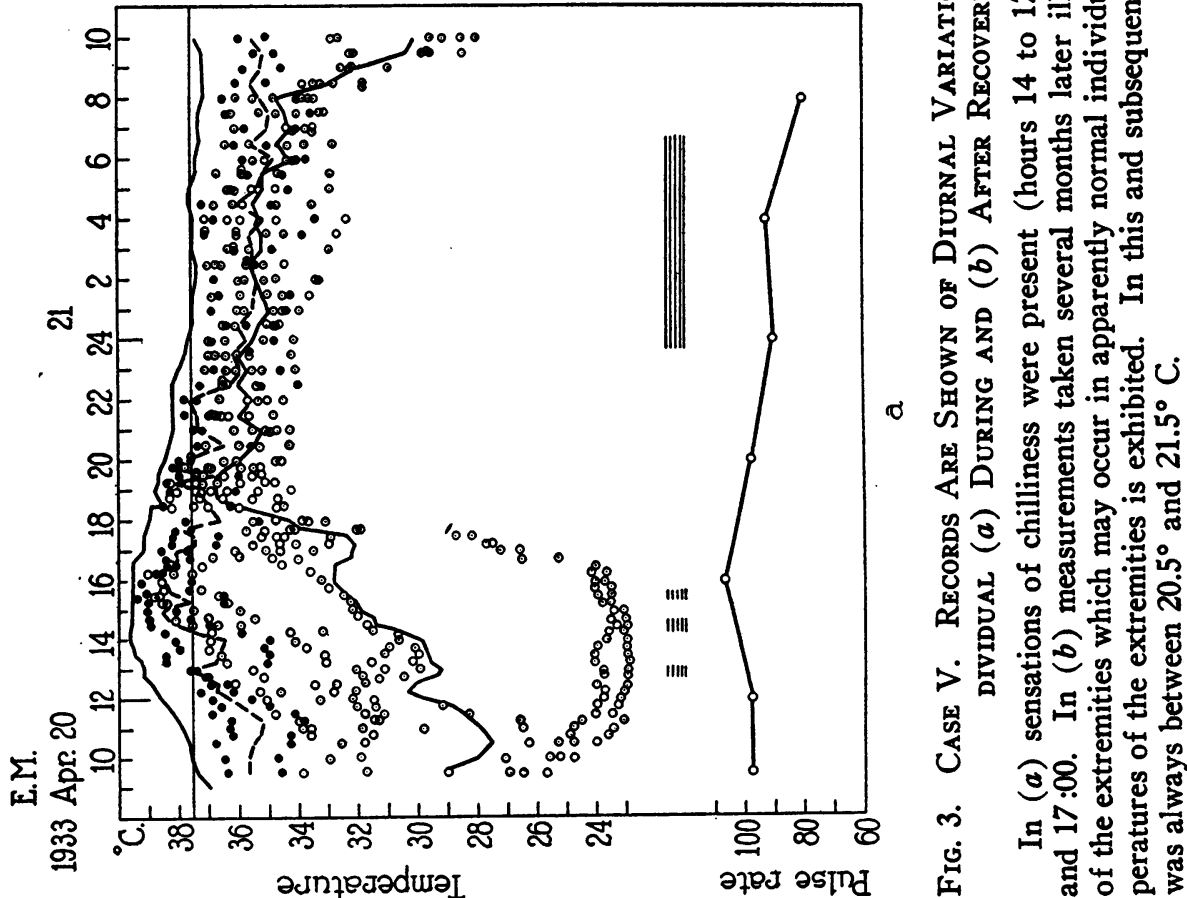




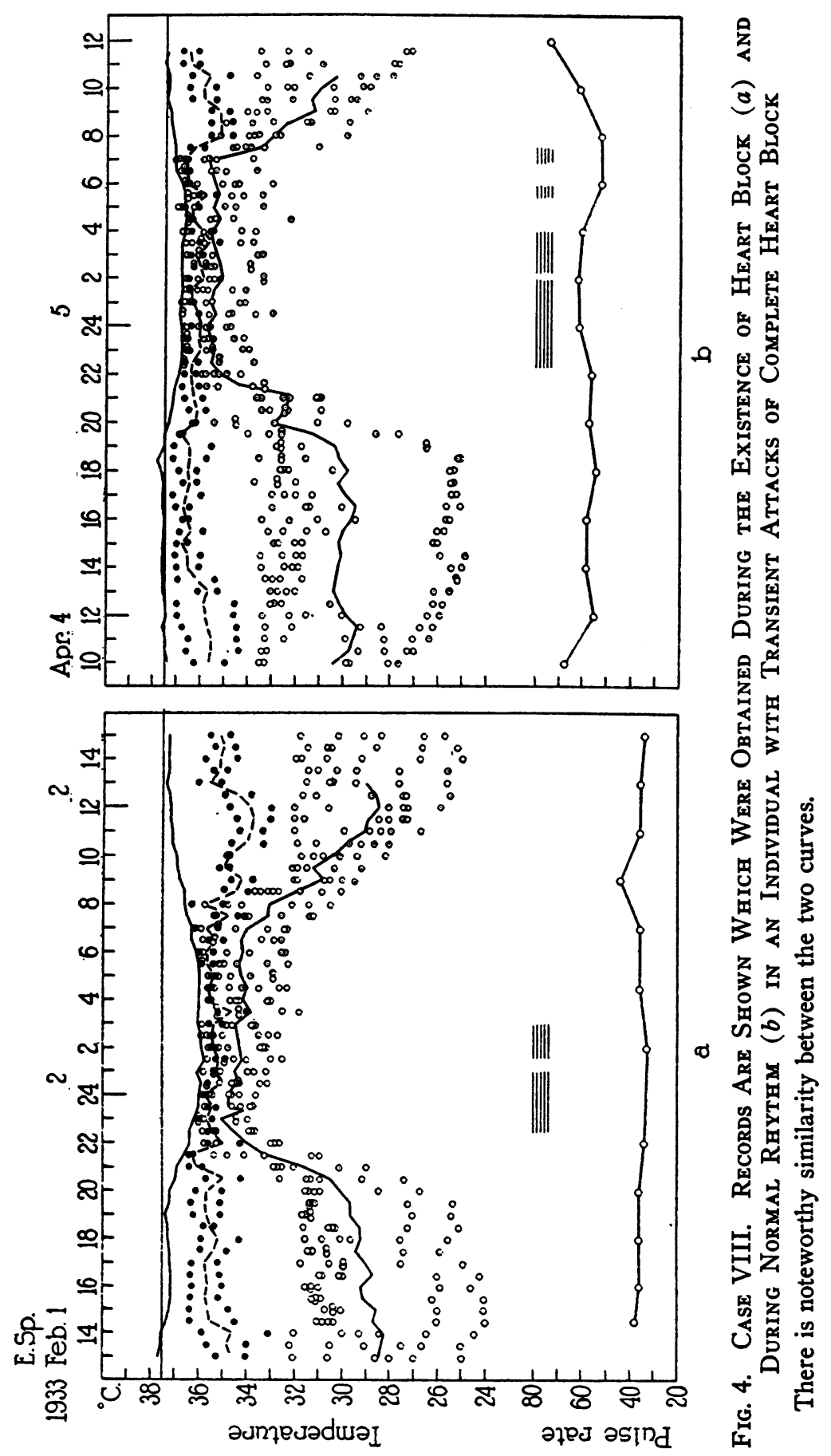


$25^{\circ}$ or $26^{\circ}$ that of the surface of the body is fairly constant and uniform (Fig. 2b). The limits of variation are $32.0^{\circ}$ and $36.4^{\circ} \mathrm{C}$. and fall within the range of Benedict's (2) observations at an environmental temperature of $25^{\circ} \mathrm{C}$. The greater uniformity and constancy obtained at this temperature obviously depend upon the fact that the temperature of the extremities does not at any time fall far below that of the trunk. They appear to be constantly occupied in radiating heat.

The circumstances under which increase in temperature of the extremities takes place are precisely those which Kirk (7) described. The rise in temperature was usually associated with drowsiness and preceded the moment of falling asleep by one-half to one and a half hours (Fig. 3b). The fact that in one of two instances recorded by Talbot (4) sleep was not associated with a rise in the temperature of the feet may have been due to the height of the room temperature $\left(24^{\circ} \mathrm{C}\right.$.). At this temperature the feet are usually already too warm to exhibit an appreciable rise. Such a situation has just been referred to in the present series (Fig. 2b). Under similar circumstances even the rise which usually follows anesthesia may not occur. Lewis and Pickering (12) have pointed out that the cooler the extremity the greater is the ensuing rise in response to warming the body. Talbot's observations were made in children and the behavior of their extremities on falling asleep may be altogether irregular. In the present study it was, however, one of the more constant relationships observed both in health and disease, in natural sleep or sleep induced by sedatives, provided that the temperature of the environment was below $22^{\circ} \mathrm{C}$.

In a number of individuals who were suffering from heart failure similar studies of surface and rectal temperatures were carried out. Observations were, however, either continued over a period of forty-eight hours, the latter half of which followed administration of large doses of digitalis, or repeated after patients had recovered from the attack of heart failure. The patients were selected because they had fever during attacks of heart failure and because at the time, evidence of the presence of hyperthyroidism, infarction, cerebral injury (hemorrhage or thrombosis) or infection was absent.

The form of diurnal variation in surface temperature obtained from individuals during heart failure with fever is similar to that observed in normal individuals. The relation between the level of diurnal variation of the interior of the body and that of the surface is, however, considerably altered. While rectal temperature is high, surface temperature is lower in heart failure than in normal subjects. The difference between surface and internal temperature is, therefore, distinctly greater than is found to be the case in normal individuals exposed to the same environmental conditions. Reduction in temperature of the surface of the extremities is marked, that of the surface of the trunk only slight (Figs. 5, 6a, Cases $\mathrm{X}, \mathrm{XI}$, respectively). The extremities remain cool for a considerably 


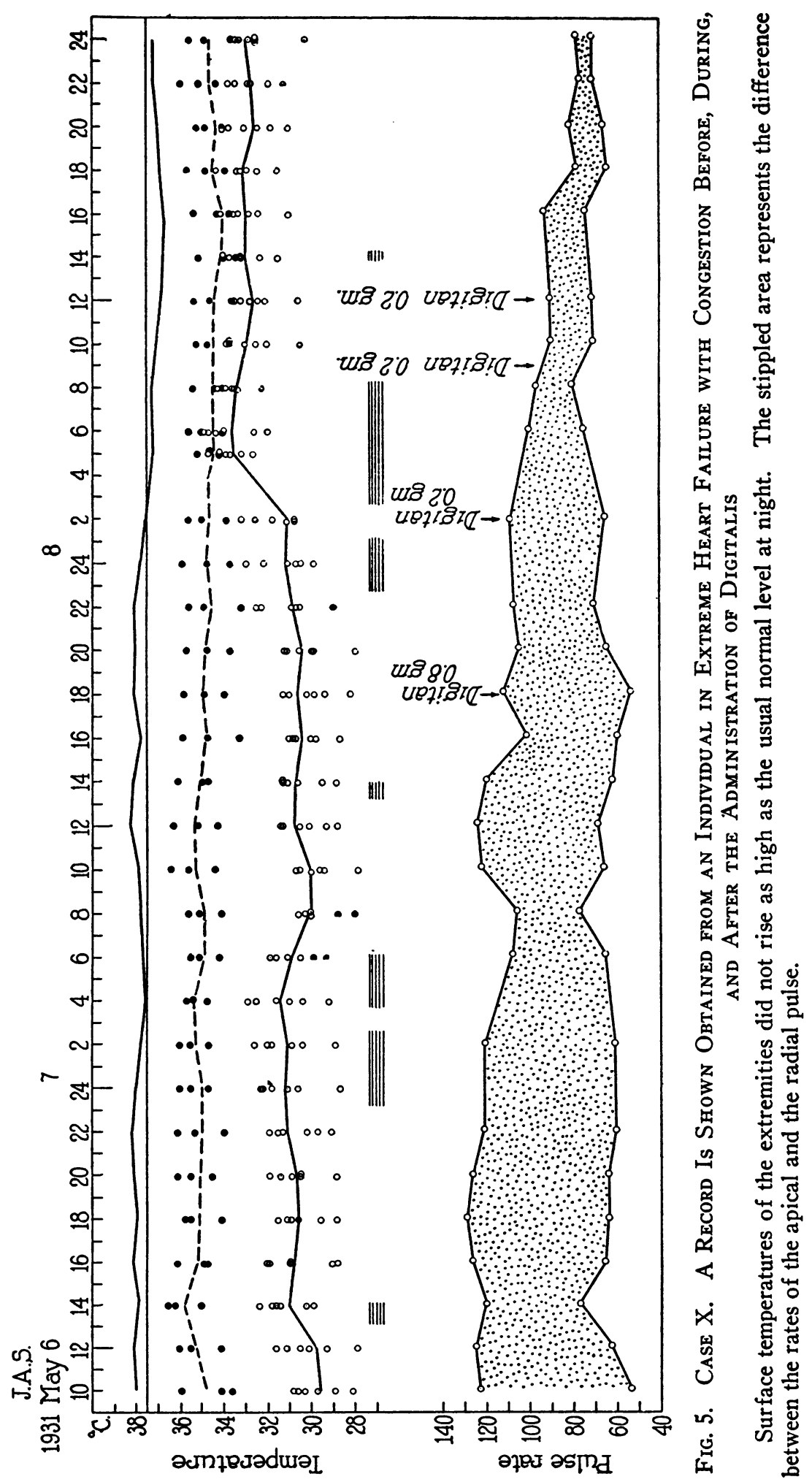




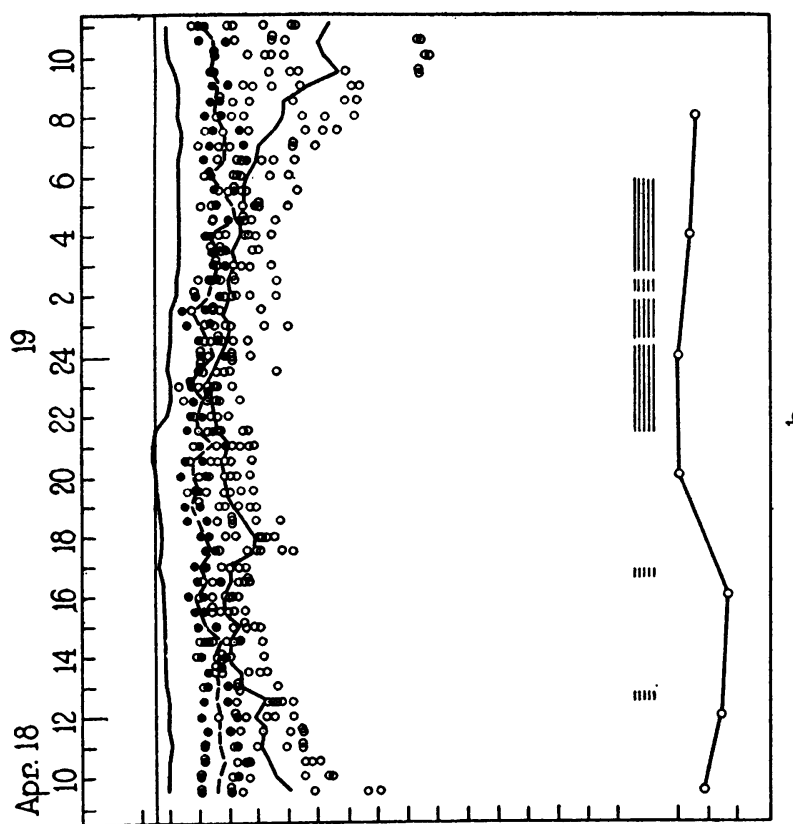

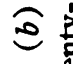

$\times 3$

온

果岁

番

会薪

- ชิ

里

灵

盾.

เัต

空

江

z.

恕

을

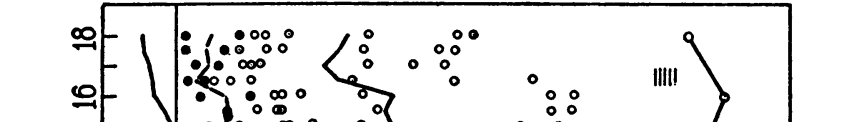

䕇

ํㅗㅇ

落

胥

实 至

엉

密.

密的

(1).

원 9.

\&

5

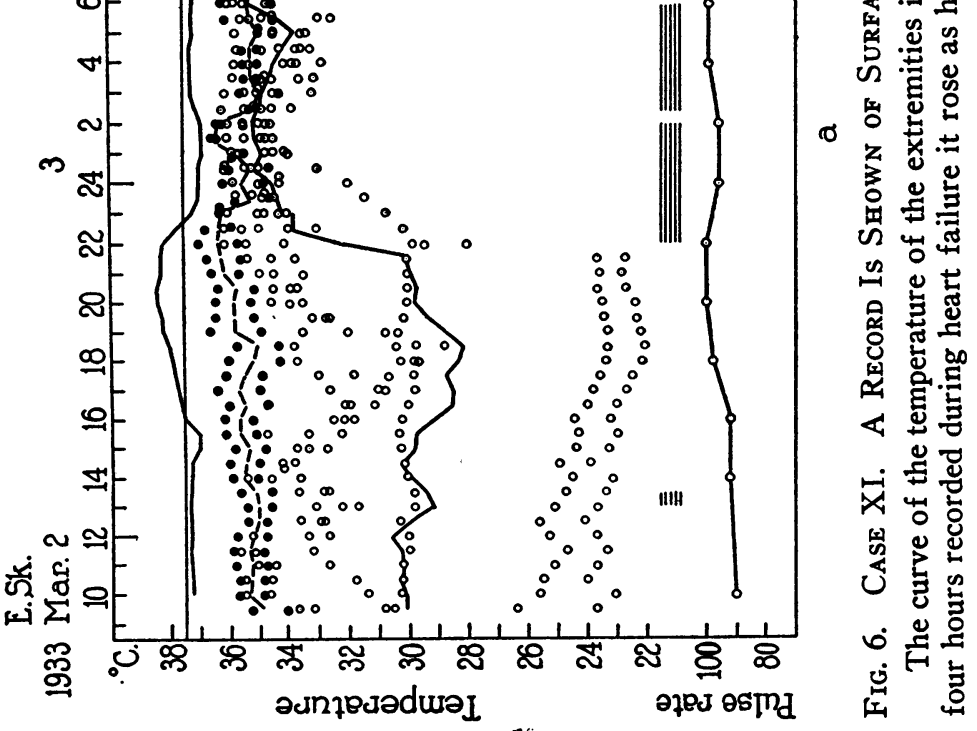


greater portion of the twenty-four hours than is normally the case. The average difference between rectal and surface temperatures for the whole period of twenty-four hours in patients with heart failure is accordingly distinctly greater than the average difference for the same period in normal subjects (Table III).

Data for a finer method of comparison are also available. The temperature of an individual in an attack of heart failure may be compared with that of the same individual after recovery (Figs. 5, 6, and Table IV). The fact that diurnal variations in a single individual are relatively constant if the physiologic state of the individual and the environmental conditions are the same enhances the value of this method of comparison. With recovery from heart failure accompanied by fever surface temperature rises and rectal temperature falls; diurnal variations become more like those of normal subjects.

The presence of edema is apparently not responsible for coolness of the surface of the extremities. That this is so can be inferred from the following observations. On two occasions digitalis was exhibited in the middle of a prolonged period of observation. In both instances decline of rectal and rise of surface temperature occurred before appreciable change in amount of edema, as evidenced by lack of change in body weight or in appearance, had taken place (Cases IX and X). In another instance change in temperature occurred in the absence of observable edema. The hands, moreover, were not edematous in any of the cases studied and yet the temperature of their surfaces rose with improvement of the circulatory state.

Fever of an infectious nature was studied in several individuals. The relation between internal and surface temperatures was found to be quite different from that in the group just described. If the various classes of individuals are described in terms of thermal gradient the magnitude of which is indicated by the difference between rectal and surface temperature, the following distinctions can be made. In individuals with infectious fevers the gradient is normal or less than normal. In individuals with heart failure and fever the gradient is greater than normal. The average internal temperature of both classes of cases with fever is roughly the same, the average surface temperature of those with infectious fever is higher than normal, of those with heart failure lower (Fig. 7). If the temperatures of the various points obtained at half-hour intervals are averaged for a period of twenty-four hours and a single difference between the average rectal and average surface temperatures is obtained, differences between the several classes are clear. In the group of cases studied during heart failure it was found that the difference between the average temperature of the rectum and that of the extremities for twenty-four hours $\left(6.5^{\circ} \mathrm{C}\right.$.) was considerably greater than that found both in the normal group $\left(3.7^{\circ} \mathrm{C}\right.$.) and in the same group after recovery from heart failure $\left(3.8^{\circ} \mathrm{C}\right.$.). In the group 


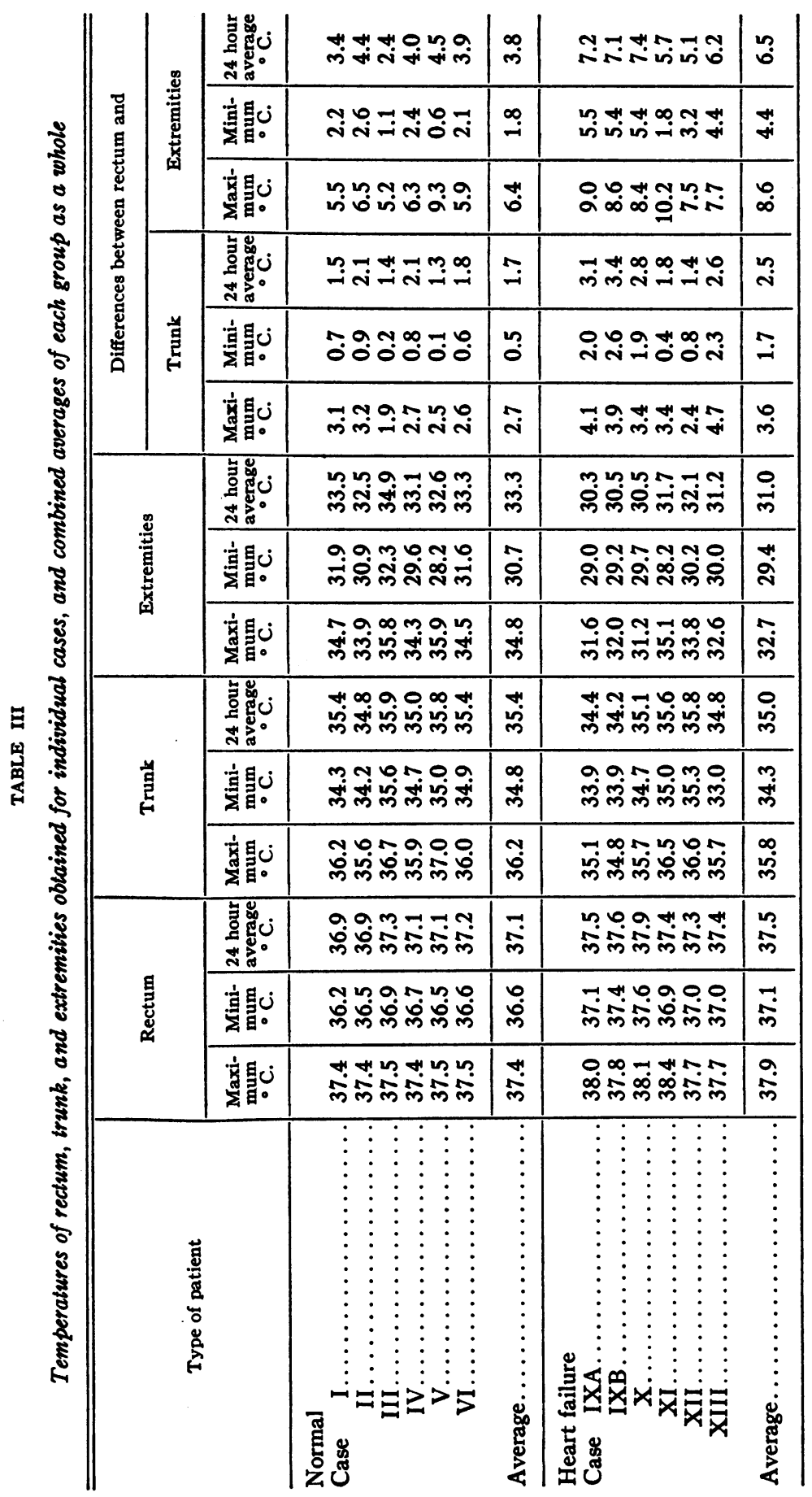


J. MURRAY STEELE

\begin{tabular}{|c|c|c|c|c|c|c|}
\hline \multirow{6}{*}{ 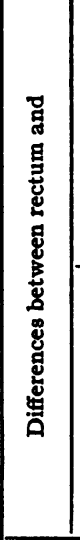 } & 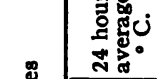 & Fテّ & $\infty$ & 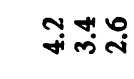 & $\stackrel{+}{m}$ & $\stackrel{n}{+}$ \\
\hline & 䒠最。 & $\stackrel{\infty}{\text { N }}$ & $\stackrel{m}{i}$ & 붕ำ & $\stackrel{0}{-}$ & i. \\
\hline & 宕最。 & ติ & ธี & 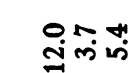 & 웅 & in \\
\hline & 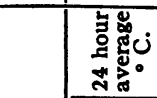 & ن̊ & $\stackrel{9}{9}$ & ت્ֹ & $\stackrel{+}{\pi}$ & กี \\
\hline & 息蝜。 & 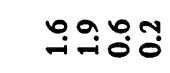 & $=$ & बें & "艹 & ò \\
\hline & 寡最。 & m户் & $\stackrel{0}{i}$ & ले & $\stackrel{\infty}{i}$ & ले \\
\hline \multirow{3}{*}{ 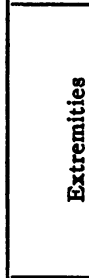 } & 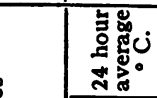 & 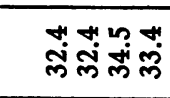 & 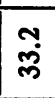 & ח户 & mें & స్లి \\
\hline & 完最。 & लि & $\frac{\text { à }}{m}$ & స్లై & $\stackrel{m}{m}$ & జ్లై \\
\hline & 宕最。 & m户̣ & mे & 象 & 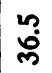 & m \\
\hline \multirow{3}{*}{ 总 } & 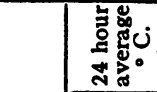 & 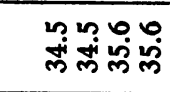 & 요 & 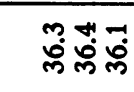 & m. & ผั่ \\
\hline & 家最。 & యैं & 芦 & 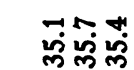 & 芦 & $\overrightarrow{+}$ \\
\hline & 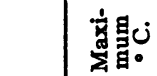 & 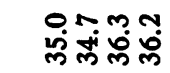 & ñ & 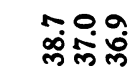 & $\frac{n}{m}$ & 웅 \\
\hline \multirow{3}{*}{\multicolumn{2}{|c|}{ 最 }} & 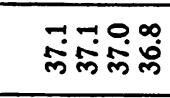 & 芦 & 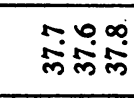 & 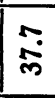 & 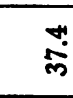 \\
\hline & & & 艿 & 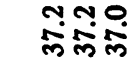 & 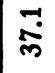 & مे \\
\hline & & 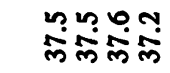 & 苞 & $\overrightarrow{\Omega^{\circ}}$ & $\vec{\infty}$ & $\stackrel{\circ}{\infty}$ \\
\hline \multicolumn{2}{|r|}{ 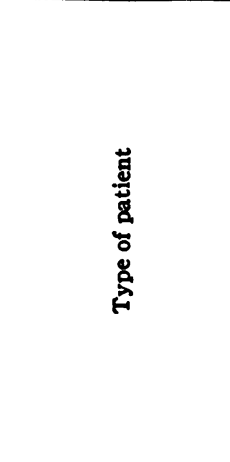 } & 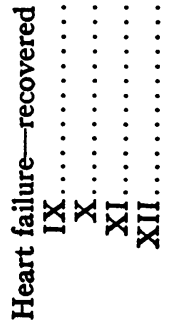 & 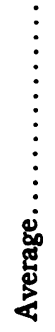 & 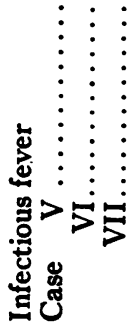 & 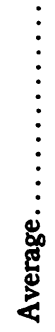 & 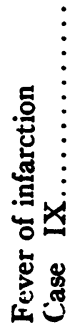 \\
\hline
\end{tabular}




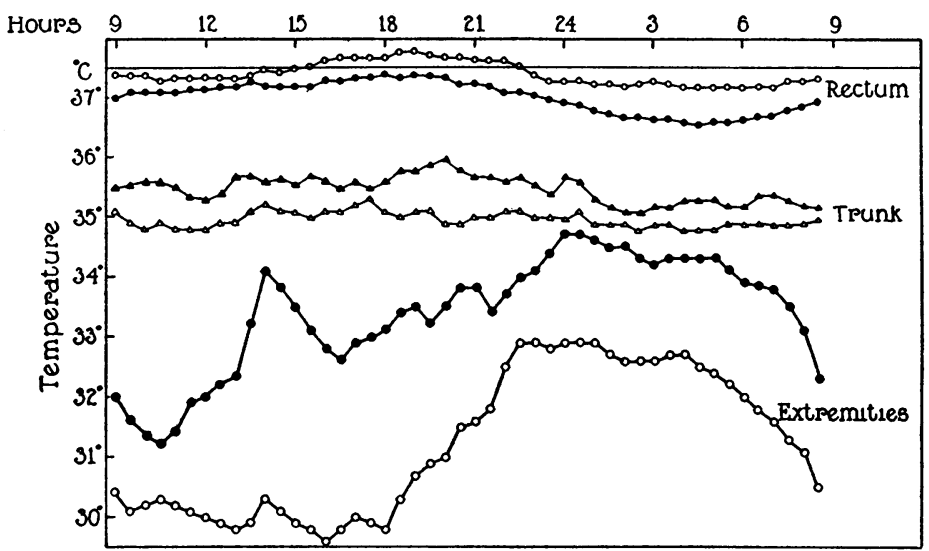

Fig. 7. The Chart Is a Composite One of Average Values of the Group of Normal Individuals and of the Group of Patients with Heart Failure.

The solid symbols trace the average curves of the normal groups; the open ones, of the group in heart failure. Note the rise of temperature of the extremities at 13 o'clock (1 P.M.) which is the beginning of the "rest hour" in hospital routine. Although several of the patients fell asleep, it is much less marked in the group of patients with heart failure.

with infectious diseases the average difference was still less $\left(3.4^{\circ} \mathrm{C}\right.$.) (Table III). Case VII, one of subacute rheumatic fever, exhibited such a relation and the temperature of the extremities failed to show the customary morning fall while the temperature was elevated (Fig. 8). Even

J.C.

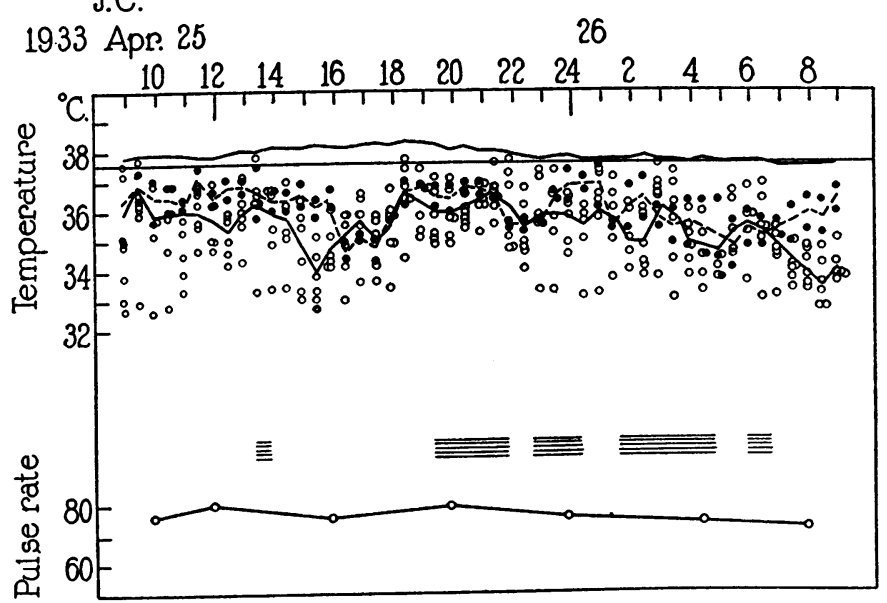

Fig. 8. Case Vil. A Record Is Exhibited Obtained from a Patient During an Attack of Acute Polyarthritis

It is similar to Figure $2 b$, a normal chart secured at a much higher environmental (room) temperature. 
when chills occur during the course of infectious fever coldness of the surface of the extremities which is present during rise of rectal temperature does not persist long enough to affect markedly the twenty-four hour average temperature of the surface. Case $\mathrm{V}$ suffered a chill while her rectal temperature was rising (Fig. 3a); the (twenty-four hour) average temperature of trunk as well as that of the extremities was higher, however, during fever than after recovery (Fig. 3b) (Table IV).

On one occasion a record of surface and rectal temperatures was obtained in a cardiac patient (Case IX) during the occurrence of fever associated with an infarct of the lungs. The average surface temperature was slightly higher than that found to exist when the patient was free of signs of heart failure and had a normal rectal temperature. 'During heart failure, with approximately the same degree of fever by rectum, the surface temperature was, as has been mentioned, much lower than after recovery (Table IV, Case IX).

One individual with well marked signs of hyperthyroidism was studied (Table IV, Case XIV). His basal consumption of oxygen was +56 per cent and rectal temperature was slightly elevated. The average surface temperature far from falling below that observed in the group of normal persons, remained near the upper limit of the group. It is perhaps of interest that the extremities failed to show the usual morning fall, and remained constantly above $33.9^{\circ} \mathrm{C}$. The chart is similar to that of Case VII, Figure 8, one of infectious disease, as well as to that of a normal individual when the room temperature is $26^{\circ} \mathrm{C}$. instead of $21^{\circ} \mathrm{C}$. (Fig. 2b).

\section{COMMENT}

Two technical matters which emerge from this study require discussion. First it is recognized that the thermocouple is not a perfect instrument for measuring surface temperatures. The fact that skin is touched at all and, in the present method, covered for a period of twenty-four hours, precludes the possibility of obtaining its temperature with accuracy due to the disturbance of the manipulations. That the skin is constantly being touched by bedclothes is not necessarily an added disadvantage. Cobet (14) from comparison of temperatures of skin calculated by measuring the radiation of heat from a known area with those measured directly by means of thermocouples, believes that the latter may be too low. His measurements agree, however, fairly well with Kunkel's (15) obtained by thermocouple. He attributes the lower results of a number of other observers to the fact that the thermocouple is not well enough protected from the influence of room air to prevent the registration of a temperature intermediate between that of the skin and that of the air. McGlone and Bazett (16) have, in a very thorough manner, shown that a large error from this source is, however, unlikely since in still room air at about $21.5^{\circ} \mathrm{C}$. the 


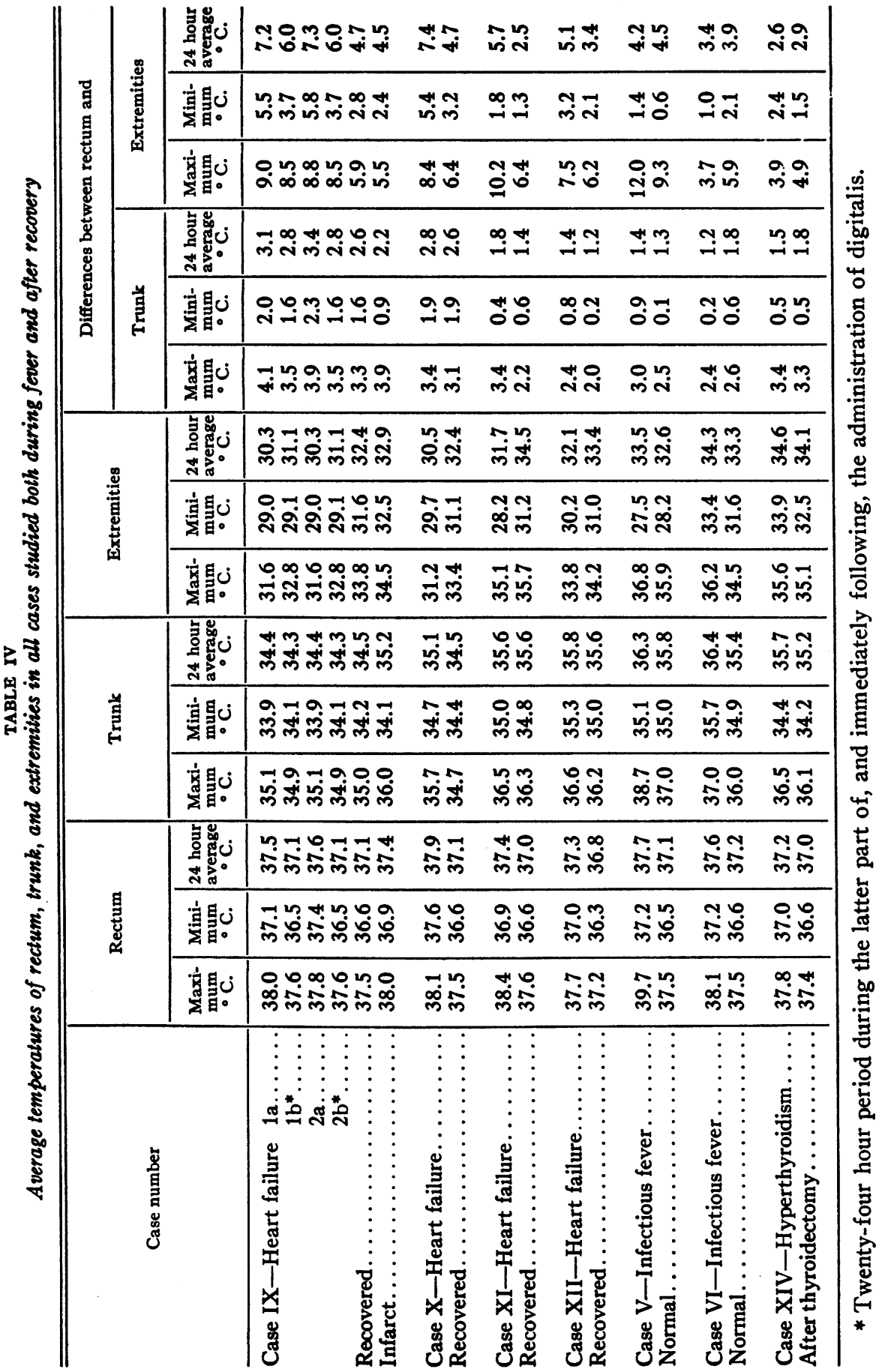


temperature of air within $1 \mathrm{~mm}$. of the surface is less than $1.0^{\circ} \mathrm{C}$. below that of the skin; and within $0.5 \mathrm{~mm}$., less than $0.2^{\circ} \mathrm{C}$. below. (The diameters of most thermal junctions are $0.3 \mathrm{~mm}$. or less.) A more frequent source of error encountered in the use of thermocouples is due to conduction of heat away from the site of measurement by the wire of the thermal junction itself. This error can be reduced, however, to less than $0.05^{\circ} \mathrm{C}$. by allowing a sufficient length of wire next the junction to come into contact with the skin or by using wire of small caliber and low conductivity. The whole error involved in making measurements by means of thermocouples of the type employed is probably not large $\left( \pm 0.5^{\circ} \mathrm{C}\right.$.) and in the present study is of little importance since relative, rather than absolute, accuracy has been sought.

The second observation concerns the choice of sites of the surface of the body for study and the significance of averaging the measurements of their temperatures; the points are not of course regarded as representing the average temperature of the whole surface. The feet and hands were given as great weight in the calculation of averages as the rest of the body because they are the regions of the body most variable in temperature and are capable of losing more heat both by radiation and evaporation than any other surface of like area. The average values of the points measured are, however, comparable from time to time since the points chosen were always the same.

It is far from surprising to find a fairly regular diurnal variation in temperature of the surface of the body. If freedom of movement and of position during periods of examination were curtailed and food witheld, many minor irregularities apparent in the present data might be eliminated. The unexpected variations encountered do not, however, obscure the regular fluctuations. Considerable interest attaches to the fact that the temperatures of the interior and of the exterior of the body (more especially the exterior of the extremities) vary in opposite directions; the rectal temperature reaches its maximum while that of the extremities is low. Then that of the extremities rises and remains elevated while the rectal temperature begins its decline. The persistent inverse relation between the two suggests at once that surface temperature regularly plays a part in regulating the extent of diurnal variation of temperature in the interior of the body. Warming certain portions of the brain (17) or the blood going to the brain (18) or warming the whole body (12) is followed uniformly by peripheral vasodilatation and lends weight to such a view. When the environment is warm enough little fluctuation in the surface temperature occurs (Fig. $2 \mathrm{~b}$ ) yet variation in rectal temperature continues. Fluctuation in the production of heat which is well known probably accounts for these changes in the rectum. To elucidate this phenomenon the variations in consumption of oxygen in one instance have been plotted (Fig. 2b).

The relation of rise of temperature of the extremities to onset of 
drowsiness or sleep, so much like the rise observed to occur at the onset of anesthesia, is interesting because it is associated with change in state of many other bodily functions. Rectal temperature decreases, heat production falls off, decrease in tone of skeletal muscle occurs, speed and accuracy of performance (19) is impaired. Even in the absence of sleep diurnal variations apparently occur. One can scarcely escape the conclusion that all of these changes are dependent upon fluctuation in the state of the entire nervous system.

Even in the presence of disease the general form of diurnal variation of internal and surface temperatures remains relatively undisturbed although the level at which variations occur and the extent of variation may be considerably altered. In fever associated with diseases of different natures these alterations appear to be different in character. The inference is that elevation of internal temperature may be brought about by more than one means.

A full explanation of the greater difference in temperature between surface and interior in patients with heart failure requires complete knowledge of all the factors involved. It is probable that the phenomenon is not always dependent upon the same train of events. In certain instances a very simple mechanism may prevail. In Case X (Fig. 5) for example, the temperature of the surface of the extremities never rose during the twentyfour hours to a point where heat was lost more rapidly than it was produced. The rectal temperature did not fall, therefore, until after the administration of digitalis. In this case the sequence of events may be similar to that occurring in a water bath designed to keep a uniform temperature and maintained by a constant source of heat near the center, after the stirring mechanism is slowed or stopped. The periphery cools, the central, continuously heated portion becomes warmer until a new and steeper gradient is reached and a new thermal equilibrium is established. Something of this sort apparently occurs also in sudden death except that - after a period of time the source of heat disappears. Attention was called in the previous paper (1) to Ackermann's observation (20) that the temperature of the body of dogs continued to rise after the heart stopped beating while the extremities cooled. That the rise of internal temperature is dependent on cessation of the circulation and not of the respiration was demonstrated by Heidenhain (21) as well as by Ackermann. The same phenomenon has been observed in man by Wunderlich (22).

A different situation is exhibited by Case XI (Fig. 6). The hands and feet remained cold during the day and the rectal temperature rose above normal. At a given time the temperature of the surface of the extremities suddenly rose, however, to a point quite as high as ever occurs in health, and the rectal temperature promptly returned to normal. A much more complex mechanism must here be operative for it is difficult to suppose that during the afternoon the heart is unable to deliver a sufficient volume of 
blood to the periphery where it loses heat accumulated in the center of the body, while early in the morning it is capable of doing so. The suggestion has been made by way of explanation that sleep provides sufficient rest to the heart muscle to allow its recuperation so that it may behave with this result (7). There is another form of explanation, however, which deserves being tested: The temperature of the central nervous connections of the vasomotor nerves is undoubtedly an important element in affecting their tone $(11,14,18,23)$. It is possible that the rate of flow of blood in the skin is so slow that its temperature when it reaches that portion of the brain concerned in vasomotor regulation is too low to bring about vasodilatation. It does so again only when it is heated to a point high enough above normal at the start of its journey to assure a proper temperature on its arrival. But the sensitivity of the central nervous structures may also for some reason not understood be impaired and, by being so, bring about the result observed.

So far discussion has been concerned quite naturally only with disturbances resulting in loss of heat since the study was planned mainly to investigate this function. Increase in the rate of production of heat would, however, obviously influence the temperature of the body. It has been shown (24) that during heart failure the consumption of oxygen may be increased. If in addition difficulties in loss of heat exist, a smaller increment in production of heat than is necessary in the presence of a normal circulation would be sufficient to elevate the rectal temperature. This must, in part, have been the situation in Case IX. In this individual the basal consumption of oxygen during heart failure varied between +22 and +28 per cent of normal and the rectal temperature was elevated. After recovery the basal metabolic rate varied between +6 and +10 per cent. But increased production of heat alone could not have been responsible for elevation of the rectal temperature for in that case the surface temperature would in all probability have been warm and not, as was the fact, cold.

Constant daily fever is, of course, often, indeed usually, absent during heart failure. The balance between production and loss of heat is so delicate an adjustment that the presence of fever in one instance and its absence in another is not surprising in view of the large number of factors which are involved in maintaining the temperature of the body. An environment of great cooling power or a low rate of heat production may prevent an unusual rise of rectal temperature in an individual in whom, under slightly different conditions, fever would occur. There exist, in fact, other mechanisms by which heat may be lost. The loss of heat by radiation from the skin accounts only for about seventy-five per cent (Benedict) of the total. If the amount of air breathed is increased sufficiently the increased loss of heat from the lungs may keep the rectal temperature from rising by compensating for a decreased loss from the skin. Hyper- 
ventilation $(24,25)$ may account for such a result. There is in addition, evidence that alteration in the insensible perspiration takes place $(26,27$, $28,29)$. Since a considerable portion of the total loss of heat from the body occurs by this means, disturbance of this function may, in itself, add or subtract an amount sufficient to elevate or lower the temperature of the rectum.

\section{SUMMARY}

Daily fluctuation of surface and rectal temperatures has been studied in normal individuals, in individuals during and after recovery from heart failure and in a few individuals suffering from infectious diseases. The patients with heart failure were selected for study because they exhibited fever and because evidence of infection was sought but was not found. A fairly regular normal diurnal variation in the temperature of the extremities opposite in direction to that of the rectal temperature is described. The behavior of the temperature of the surface of the body, especially of the extremities, in the cases of heart failure which exhibit fever of unexplained source is different from that observed in patients with fever associated with infectious diseases. The temperature of the surface in cardiac patients is lower than that of normal individuals while that of patients with infectious fever is as high as, or higher than, normal. The difference in behavior leads to the conclusion that elevation of rectal temperature in cases of heart failure need not be of infectious origin but may depend upon a variety of processes incident to heart failure itself.

\section{BIBLIOGRAPHY}

1. Cohn, A. E., and Steele, J. M., Unexplained fever in heart failure. J. Clin. Invest., 1934, 13, 853.

2. Benedict, F. G., Die Temperatur der menschlichen Haut. Ergebn. d. Physiol., 1925, 24, 594.

3. Benedict, F. G., and Parmenter, H. S., Human skin temperature as affected by muscular activity, exposure to cold, and wind movement. Am. J. Physiol., 1928-29, 87, 633.

4. Talbot, F. B., Skin temperatures of children. Am. J. Dis. Child., 1931, 42, 965.

5. Foged, J., Die normale Hauttemperatur. Skandinav. Arch. f. Physiol., 1932, 64, 251.

6. Ward, E. F., The measurement of skin temperature in its relation to the sensation of comfort. Am. J. Hyg., 1930, 12, 130.

7. Kirk, E., Untersuchungen über den Einfluss des normalen Schlafes auf die Temperatur der Füsse. Skandinav. Arch. f. Physiol., 1931, 61, 71.

8. Ipsen, J., Maalinger af Hudtemperaturer ved kirurgiske Sygdomme. Hospitalstid., 1925, 68, 944 and 953.

9. White, J. D., Diagnostic blocking of sympathetic nerves to extremities with procaine. A test to evaluate the benefit of sympathetic ganglionectomy. J. A. M. A., 1930, 94, 1382.

10. Morton, J. J., and Scott, W. J. M., The measurement of sympathetic vasoconstrictor activity in the lower extremities. J. Clin. Invest., 1931, 9. 235. 
11. Gibbon, J. H., Jr., and Landis, E. M., Vasodilatation in the lower extremities in response to immersing the forearms in warm water. J. Clin. Invest., 1932, 11, 1019.

12. Lewis, T., and Pickering, G. W., Vasodilation in the limbs in response to warming the body with evidence for sympathetic vasodilator nerves in man. Heart, 1931-33, 16, 33.

13. Clark, H., The measurement of intravenous temperatures. J. Exper. Med., 1922, 35, 385.

14. Cobet, R., und Bramigk, F., Utber Messung der Wärmestrahlung der menschlichen Haut und ihre klinische Bedeutung. Deutsches Arch. f. klin. Med., 1924, 144, 45.

15. Kunkel, A. J., Ueber die Temperatur der menschlichen Haut. Ztschr. f. Biol., 1889, 25, 55.

16. McGlone, B., and Bazett, H. C., The temperature of the air in contact with the skin. Am. J. Physiol., 1927, 82, 452.

17. Kahn, R. H., Ueber die Erwärmung des Carotidenblutes. Arch. f. Anat. u. Physiol., 1904 (Suppl.-Bd.), page 81.

18. Barbour, H. G., and Prince, A. L., The control of the respiratory exchange by heating and cooling the temperature centers. J. Pharmacol. and Exper. Therap., 1914-15, 6, 1.

19. Kleitman, N., Studies on the physiology of sleep. VIII. Diurnal variation in performance. Am. J. Physiol., 1933, 104, 449.

20. Ackermann, 'Th., Ueber die physiologischen Wirkungen des Digitalins auf den Kreislauf und die Temperatur. Deutsches Arch. f. klin. Med., 1873, $11,125$.

21. Heidenhain, R., Ueber bisher unbeachtete Einwirkungen des Nervensystems auf die Körpertemperatur und den Kreislauf. Arch. f. d. ges. Physiol., $1870,3,504$.

22. Wunderlich, C. A., On the Temperature in Diseases. A manual of medical thermometry. The New Sydenham Society, London, 1871. Translated by Woodman, W. B., from $2 d$ German edition.

23. Pickering, G. W., The vasomotor regulation of heat loss from the human skin in relation to external temperature. Heart, 1931-33, 16, 115.

24. Peabody, F. W., Wentworth, J. A., and Barker, B. I., Clinical studies on the respiration. V. The basal metabolism and minute-volume of the respiration of patients with cardiac disease. Arch. Int. Med., 1917, 20, 468.

25. Harrison, T. R., Turley, F. C., Jones, E., and Calhoun, J. A., Congestive heart failure. $X$. The measurement of ventilation as a test of cardiac function. Arch. Int. Med., 1931, 48, 377.

26. Eimer, K., and Voigt, W., Rohkoststudien. II. Die Rohkostbehandlung des dekompensierten Kreislaufs. Ztschr. f. klin. Med., 1930, 112, 477.

27. Zak, E., Uber das Verhalten der Perspiratio insensibilis und des Körpergewichtes bei dekompensiertem Kreislauf. Ztschr. f. klin. Med., 1929, $110,44$.

28. Stratmann, F. W., Die Perspiratio insensibilis bei Kreislaufkranken. Inaugural-Dissertation, Würzburg, 1931.

29. Conti, F., La Perspiratio insensibilis nei cardiopatici scompensati. Minerva Med., 1932, 2, 789. 